\title{
Isolation and characterization of novel microsatellite loci in the wrinkled frog
}

\author{
D.Y. Kim ${ }^{1 *}$, D. Kim ${ }^{2 *}$, S.K. Park ${ }^{2}$, H. Lee ${ }^{1}$, H.Y. Suk ${ }^{2}$ and M.S. Min ${ }^{1}$ \\ ${ }^{1}$ Conservation Genome Resource Bank for Korean Wildlife, \\ Research Institute for Veterinary Science, College of Veterinary Medicine, \\ Seoul National University, Gwanak-gu, Seoul, South Korea \\ 2Department of Life Sciences, Yeungnam University, Gyeongsan, \\ Gyeongsangbuk-do, South Korea \\ *These authors contributed equally to this study. \\ Corresponding authors: H.Y. Suk / M.S. Min \\ E-mail: hsuk@ynu.ac.kr/minbio@yahoo.co.kr \\ Genet. Mol. Res. 15 (1): gmr.15017183 \\ Received August 10, 2015 \\ Accepted October 5, 2015 \\ Published January 13, 2016 \\ DOI http://dx.doi.org/10.4238/gmr.15017183
}

\begin{abstract}
The wrinkled frog, Rana rugosa, is a species complex that inhabits plains and mountains near freshwater bodies throughout East Asia, encompassing China, Korea, Japan, and the Russian Primorye region. Although extensive efforts are required to estimate cryptic diversity in the $R$. rugosa complex, no specifically designed microsatellite loci are available. Here, novel and polymorphic microsatellites were isolated based on the construction of a microsatellite-enriched library and characterized using $R$. rugosa specimens collected on the Korean Peninsula. A total of 72 primer sets were designed from approximately 400 positive clones, and 22 were validated as being reliably amplified and polymorphic. Overall, high genetic variability was observed (mean number of alleles per locus = 22.23; mean observed and expected heterozygosities $=0.770$ and 0.816 , respectively) from a total of 60 individuals sampled from two geographically isolated localities. In the two sites analyzed, an extremely low level of relatedness was inferred from the estimation of pairwise relatedness, and no evidence of a genetic bottleneck was detected. The two sites showed a
\end{abstract}


high level of genetic differentiation, suggesting a clear signature of isolation following colonization. With high statistical power in parentage and sibship exclusion, these microsatellite loci will be suitable for the identification of cryptic diversity and population structure as well as the recognition of individuals in social interaction and captive breeding practice.

Key words: Wrinkled frogs; Rana rugosa; Rana emeljanovi; Microsatellites; Ranidae

\section{INTRODUCTION}

Since the late 1980s, declines in amphibian populations have occurred more frequently across the globe (Crawford et al., 2010; Hayes et al., 2010), and approximately one-third of all recorded species are presently threatened with extinction (Stuart et al., 2004). Despite this unprecedented worldwide crisis, the discovery of new amphibian species has increased explosively, as a result of the rigorous application of molecular tools in recent years (Hanken, 1999; Wynn and Heyer, 2001; Gower et al., 2005; Lemmon et al., 2007), indicating that the level of amphibian diversity has thus far been greatly underestimated (Vieites et al., 2009; Nair et al., 2012). Indeed, efforts to recognize hidden lineages or species could be regarded as a critical foundation for the development of long-term management programs in amphibian species, such as delineating conservation priorities and setting protection/recovery strategies.

The wrinkled frog, Rana rugosa, is a type of true frog that generally inhabits plains and mountains near freshwater bodies, and provides a model system for investigating cryptic diversity within taxa previously regarded as a single species. This species is widely distributed across East Asia encompassing China, Korea, Japan, and the Russian Primorye region (Máeda and Matsui, 1999; Yang et al., 2000). Uncertainty still remains concerning its taxonomic status. R. rugosa is a species complex that likely represents at least three different species (Frost et al., 2006; Sekiya et al., 2012); $R$. emeljanovi in east China and the Korean Peninsula, $R$. rugosa in Japan, and $R$. tientaiensis in central China. In addition, recent studies based on molecular and cytogenetic tools clearly showed that five distinct lineages (species candidate) of $R$. rugosa exist in Japan (Miura, 2007; Sekiya et al., 2012). Recently, R. rugosa populations from Sado Island in Japan were found to be phenotypically distinct and postzygotically isolated from other $R$. rugosa populations, and were described as a new species, which was named $R$. susurra (Sekiya et al., 2012).

It is imperative that extensive efforts are made to identify cryptic diversity in the $R$. rugosa complex across EastAsia, especially given the rising likelihood of habitat degradation and extirpation in many areas (Stuart et al., 2004). Although microsatellites may provide an appropriate solution to evaluate population structure and to find cryptic lineages, no specifically designed microsatellite loci are currently available. Here, 22 novel and polymorphic microsatellites were isolated and characterized using a specimen of $R$. rugosa ( $R$. emeljanovi) collected from the Korean Peninsula.

\section{MATERIAL AND METHODS}

\section{Sample collection}

Sampling and tissue collection were carried out under the national legislation of South Korea. A total of 60 individuals were sampled during 2012 and 2013 from two localities (Yangsan 
and Jincheon) on the Korean Peninsula. Yangsan is on the southeastern side of the peninsula

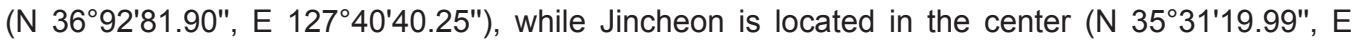
$\left.129^{\circ} 06^{\prime} 86.52^{\prime \prime}\right)$. Those two localities are separated by complicated landscape structures and an approximate distance of more than $200 \mathrm{~km}$ (straight line distance).

\section{Microsatellite isolation}

For microsatellite isolation, a microsatellite-enriched library was constructed based on previously employed protocols (Suk et al., 2009; Park et al., 2014). Genomic DNA was extracted from the first toe tissues of five individuals (from Yangsan) using the Wizard Genomic DNA purification kit (Promega, Fitchburg, WI, USA) based on the manufacturer protocol, and was subsequently digested with Mbol (Enzynomics, Daejeon, South Korea). DNA fragments of 500$1000 \mathrm{bp}$ in size were isolated by gel elution and then ligated to a double-stranded adaptor (EP; forward: 5'-CCC CCA CCT CCT GCC CAT CAT AAAAAA TC-3'; reverse: 5'-phosphate - GAT CGA TTT TTT ATG ATG GGC AGG AGG TGG GGG-3') using T4 DNA ligase (Enzynomics). The ligated fragments were recovered by polymerase chain reaction (PCR; annealing at $65^{\circ} \mathrm{C}$ ) with the primer EP3 (5'-CCC CCA CCT CCT GCC ATC AT-3'). The PCR product was purified and hybridized to biotinylated $(\mathrm{GT})_{12}$ and $(\mathrm{CT})_{12}$ probes $\left(65^{\circ} \mathrm{C}\right.$ for $\left.12 \mathrm{~h}\right)$. The hybridized fragments were isolated using streptavidin-coated magnetic beads (Promega) and recovered by PCR using the EP3 primer. The PCR products were ligated into a pGEM-T Easy Vector (Promega). The ligated vector was transformed into $\mathrm{DH} 5 \alpha$ cells (Enzynomics) and spread onto LB-ampicillin agar plates containing IPTG and X-gal. About 400 positive clones were chosen and sequenced at NICEM (Seoul National University, Seoul, South Korea) with M13 (-40) forward and reverse universal primers.

\section{Validation and genotyping}

Flanking regions of the sequences were used to design microsatellite PCR primer sets. Each forward primer of the validated sets was fluorescently labeled with FAM, HEX, and TET (Cosmo Genetech, Seoul, South Korea; Table 1). PCR amplifications were carried out for each primer set on a GenePro thermocycler (BIOER, Hangzhou, China). Thermal cycling consisted of an initial denaturation step at $94^{\circ} \mathrm{C}$ for $5 \mathrm{~min}$, followed by 35 cycles comprising $94^{\circ} \mathrm{C}$ for $30 \mathrm{~s}, 54^{\circ}$ $58^{\circ} \mathrm{C}$ for $30 \mathrm{~s}, 72^{\circ} \mathrm{C}$ for $30 \mathrm{~s}$, and a final extension at $72^{\circ} \mathrm{C}$ for $10 \mathrm{~min}$. The fluorescently labeled PCR products were genotyped on an ABI 3730xl Genetic Analyzer (NICEM) and scored using GeneMapper 3.7 (Applied Biosystems, Foster City, CA, USA). Those polymorphic markers were deposited in GenBank under the accession Nos. KR259851-KR259873.

\section{Statistical analysis}

Characteristics of the 22 polymorphic loci, the number of alleles, expected $\left(H_{E}\right)$ and observed $\left(H_{\mathrm{O}}\right)$ heterozygosity, and inbreeding coefficient $\left(F_{\mathrm{IS}}\right)$ were estimated using Genepop ver. 4.2 (Raymond and Rousset, 1995) and Arlequin 3.5 (Excoffier and Lischer, 2010). Allelic richness was estimated using FSTAT ver. 2.9.3.2 (Goudet, 2001). Departures of genotypic proportions from those predicted under Hardy-Weinberg equilibrium (HWE) were tested for each locus-site combination using Genepop with the exact test following Markov chain parameters with 1000 batches and 10,000 iterations per batch (Guo and Thompson, 1992). The Fisher exact test of 
Table 1. Characterization of 22 polymorphic microsatellite loci for Rana rugosa and a summary of genetic diversity indices, being comprised of locus name, primer sequence, GenBank accession No. (Acc. No.), repeat motif ( $R$-Motif), number of alleles per locus $\left(N_{\mathrm{A}}\right)$, allele size range $(\mathrm{bp})$, observed $\left(H_{\mathrm{O}}\right)$ and expected $\left(H_{\mathrm{E}}\right)$ heterozygosities, inbreeding coefficient $\left(F_{\mathrm{IS}}\right)$, and pairwise- $F_{\mathrm{ST}}$ between two sites.

\begin{tabular}{|c|c|c|c|c|c|c|c|c|c|c|}
\hline Locus & Primer sequence $\left(5^{\prime} \rightarrow 3^{\prime}\right)$ & Flu & Acc. No. & $R$-Motif & $N_{\mathrm{A}}$ & $\mathrm{bp}$ & $H_{0}$ & $H_{\mathrm{E}}$ & $F_{\mathrm{IS}}$ & $F_{\mathrm{ST}}$ \\
\hline Gr001 & $\begin{array}{l}\text { F-TGAGCTACTCCTCCCATCTTGA } \\
\text { R-GGCAGGGGTGACATGTATGA }\end{array}$ & HEX & KR259851 & $(\mathrm{GT})_{19}$ & 26 & $142-208$ & 0.932 & 0.941 & 0.009 & 0.016 \\
\hline Gr002 & $\begin{array}{l}\text { F-TCGGCTGTGTGAAGAAAGGT } \\
\text { R-ACCACTTTTATCCACAGAGACACA }\end{array}$ & TET & KR259852 & $(\mathrm{GT})_{25}$ & 19 & $130-180$ & 0.751 & 0.797 & 0.053 & 0.142 \\
\hline Gr004 & $\begin{array}{l}\text { F-ATCCTGCTTCCTTTCACCGC } \\
\text { R-TGGATTAAACAAGAAGCACAGCA }\end{array}$ & TET & KR259853 & $(\mathrm{GA})_{13}-(\mathrm{GA})_{17}$ & 7 & $100-174$ & 0.334 & 0.272 & -0.230 & 0.171 \\
\hline Gr006 & $\begin{array}{l}\text { F-GTGATGCCGTTTAGATGAAGTT } \\
\text { R-CACCTCTTAAAGTGTGTGATTGAT }\end{array}$ & HEX & KR259854 & $(\mathrm{CA})_{29}$ & 24 & 108-187 & 0.779 & 0.870 & 0.097 & 0.131 \\
\hline Gr008 & $\begin{array}{l}\text { F-TTCATATCATCGCCCTCCCC } \\
\text { R-CTCCCACCCTCCATTCAAGG }\end{array}$ & TET & KR259855 & $(\mathrm{GT})_{26}$ & 17 & 214-283 & 0.870 & 0.842 & -0.030 & 0.071 \\
\hline Gr015 & $\begin{array}{l}\text { F-TGAGAGTCAATCACAGCCTGT } \\
\text { R-CGTGCAGGTTTGTTTCCGAG }\end{array}$ & 6-FAM & KR259856 & $(\mathrm{GT})_{35}-(\mathrm{GT})_{4}-(\mathrm{GT})_{3}$ & 34 & $111-215$ & 0.822 & 0.884 & 0.127 & 0.061 \\
\hline Gr017 & $\begin{array}{l}\text { F-TCO } \\
\text { R-GC }\end{array}$ & 6-FAM & KR259857 & $(\mathrm{CA})_{23}$ & 28 & $173-254$ & 0.884 & 0.934 & 0.056 & 0.035 \\
\hline Gr023 & $\begin{array}{l}\text { F-TT } \\
\text { R-CA }\end{array}$ & TET & KR259858 & $(\mathrm{GT})_{23}$ & 21 & $156-249$ & 0.829 & 0.840 & 0.014 & 0.006 \\
\hline Gr024 & $\begin{array}{l}\text { F-TG } \\
\text { R-TC }\end{array}$ & HEX & KR259859 & $(\mathrm{GT})_{22}$ & 21 & $221-278$ & 0.750 & 0.865 & 0.133 & 0.103 \\
\hline Gr029 & $\begin{array}{l}\text { F-CCC } \\
\text { R-AGC }\end{array}$ & TET & KR259860 & $(\mathrm{GT})_{31}$ & 30 & $179-271$ & 0.918 & 0.897 & -0.027 & 0.065 \\
\hline Gr030 & $\begin{array}{l}\text { F-GCO } \\
\text { R-GTC }\end{array}$ & TET & KR259861 & $(\mathrm{TG})_{24}(\mathrm{TA})_{5}$ & 16 & 133-191 & 0.492 & 0.597 & 0.169 & 0.357 \\
\hline Gr032 & $\begin{array}{l}\text { F-CAGC } \\
\text { R-TCC }\end{array}$ & 6-FAM & KR259863 & $(\mathrm{TG})_{27}(\mathrm{TAGA})_{5}(\mathrm{GA})_{2}$ & 24 & $116-317$ & 0.850 & 0.934 & 0.090 & 0.040 \\
\hline Gr033 & $\begin{array}{l}\text { F-TGGCAGTTACATAGTTGAAGACA } \\
\text { R-ATTGACCGCTGCAATATCGC }\end{array}$ & HEX & KR259864 & $(\mathrm{TG})_{43}(\mathrm{TA})_{4}$ & 42 & $95-281$ & 0.927 & 0.943 & 0.017 & 0.039 \\
\hline Gr034 & $\begin{array}{l}\text { F-GCTGGAACTCAACTTTCTGTGTC } \\
\text { R-CAGTAGCTCTCACAGACAAAGC }\end{array}$ & HEX & KR259865 & $(\mathrm{TCTA})_{15}-(\mathrm{TCTA})_{10}$ & 26 & $144-271$ & 0.872 & 0.925 & 0.052 & 0.038 \\
\hline Gr035 & $\begin{array}{l}\text { F-AGCTCTCCTCTGTCCCTCTG } \\
\text { R-GGCTGGATAAAAGAGAGGGATTG }\end{array}$ & TET & KR259866 & $(\mathrm{TG})_{29}-(\mathrm{TG})_{5}$ & 18 & 125-199 & 0.692 & 0.657 & -0.056 & 0.312 \\
\hline Gr037 & $\begin{array}{l}\text { F-CCCGGTTGGTAAGTGGTTT } \\
\text { R-TCTACTGGGCCCTTTTAAAACA }\end{array}$ & HEX & KR259867 & $(\mathrm{GT})_{22}$ & 18 & $152-186$ & 0.851 & 0.893 & 0.046 & 0.057 \\
\hline Gr038 & $\begin{array}{l}\text { F-CCCCATAGAGACATGCCGAT } \\
\text { R-CCCTGAAATCTGAGAGGCCA }\end{array}$ & 6-FAM & KR259868 & $(\mathrm{GT})_{37}$ & 19 & 92-204 & 0.638 & 0.765 & 0.166 & 0.033 \\
\hline Gr043 & $\begin{array}{l}\text { F-CTGTACAGTCGCATGTGATTG } \\
\text { R-AATGGTAATCGTTCGCTCCT }\end{array}$ & 6-FAM & KR259869 & $(\mathrm{AT})_{3}(\mathrm{GT})_{12}-(\mathrm{GT})_{9}$ & 18 & $192-274$ & 0.822 & 0.884 & 0.089 & 0.038 \\
\hline Gr051 & $\begin{array}{l}\text { F-AGGCTTCTCTGAATGGGCA } \\
\text { R-GGTCTTCCCTGAACATAATGGAC }\end{array}$ & 6-FAM & KR259870 & $(\mathrm{GT})_{24}(\mathrm{CT})_{8}$ & 25 & $112-194$ & 0.810 & 0.818 & 0.009 & 0.016 \\
\hline Gr053 & $\begin{array}{l}\text { F-CCTGTGGTGAAGGAGAGGAG } \\
\text { R-TTGTTGTGGAGAGGGGTCTG }\end{array}$ & 6-FAM & KR259871 & $(\mathrm{GT})_{27}$ & 23 & $172-259$ & 0.637 & 0.721 & 0.123 & 0.259 \\
\hline Gr054 & $\begin{array}{l}\text { F-TCCACATGCACTGCTCTTCT } \\
\text { R-AGTAGTGCCCCTCCATAGCA }\end{array}$ & HEX & KR259872 & $(\mathrm{TG})_{24}$ & 14 & $100-174$ & 0.715 & 0.744 & 0.038 & 0.234 \\
\hline Gr055 & $\begin{array}{l}\text { F-AGGTATGGAAAGGTCATGCTGT } \\
\text { R-AGCTCCTTGACTGCCAACAA }\end{array}$ & HEX & KR259873 & $(\mathrm{GT})_{32}-(\mathrm{GT})_{2}$ & 19 & 137-191 & 0.764 & 0.874 & 0.123 & 0.068 \\
\hline
\end{tabular}

linkage disequilibrium between all pairs of loci disclosed presumed gametic disequilibria for all paired loci in every population under the Markov chain parameters in Genepop. Critical significance values were corrected for multiple tests by the sequential Bonferroni correction (Rice, 1989). Bottleneck ver. 1.2.02 (Piry et al., 1999) was used to examine the possibility of a recent reduction in population size based on a significant excess of $H_{\mathrm{E}}$ under mutation-drift equilibrium relative to HWE with three different models of microsatellite mutation, infinite allele model (IAM), stepwise mutation model (SMM) and two-phased model (TPM), with the proportion of SMM $=70 \%$ and IAM $=30$. Genetic divergence between two analyzed sites was assessed by calculating the pairwise$F_{\mathrm{ST}}$ and $-R_{\mathrm{ST}}$ in Genepop. Relatedness for each pair of individuals within sites was determined in ML-Relate (Kalinowski et al., 2006). 


\section{RESULTS AND DISCUSSION}

About 400 positive clones were selected for sequencing. A total of 72 microsatellite PCR primer sets were designed using the Primer 3 program (ver. 0.4.0; http://bioinfo.ut.ee/primer3-0.4.0/) and screened using 12 individuals from Yangsan. Primer sets were discarded if they failed to amplify consistently and were monomorphic. From 72 primer sets, 22 were validated and were reliably amplified and clearly polymorphic in the 12 individuals.

From a total of 60 individuals sampled from two geographically isolated sites (Yangsan and Jincheon), high genetic variability was observed at the 22 loci examined (Table 1). The average number of alleles per locus was 22.23, ranging from 7 (Gro04) to 42 (Gro33). The average $H_{\circ}$ and $H_{\mathrm{E}}$ were 0.770 and 0.816 , respectively, ranging from 0.334 (Gro04) to 0.932 (Gro01), and 0.272 (Gr004) to 0.943 (Gro33), respectively. A single locus (Gr053) showed a significant deviation in genotype proportion from HWE after Bonferroni correction $(\mathrm{N}=22, \alpha=0.0023)$ owing to a significant deficiency in the observed number of heterozygotes. At the population level, a significant heterozygosity deficiency was found for Gr043 and Gr053 from Yangsan and for Gr006 from Jincheon. Such deviations might arise from a failure of amplification of one allele or because of an allele size falling outside of the normal calling range. The Fisher exact test revealed significant disequilibrium for only 10 of the possible pairs of the 22 loci (231 pairs) after sequential Bonferroni correction ( $N=44, \alpha=0.0011$ ), indicating that there was no likelihood of linkage between loci or population subdivision within sampling sites.

The two sampling sites showed similar levels of genetic variation (allelic richness; Table 2). No signature of a genetic bottleneck was detected, since no significant excess of $H_{\mathrm{E}}$ under mutationdrift equilibrium relative to that observed under HWE was detected based on the Wilcoxon test (Table 2). In addition, the Bottleneck program did not reveal any signature of a population decline with the test of shift in allele class distribution mode (normal L-shaped distribution). In future studies with widespread sampling, the $M$-ratio and critical $M$ (Garza and Williamson, 2001) can also be calculated and compared with the results of the Bottleneck program to find historical signatures of population decline during colonization and genetic divergence among populations.

Table 2. Genetic diversity parameters for two sites of Rana rugosa sampling, Yangsan and Jincheon, being comprised of total number of individuals analyzed $(\mathrm{N})$, mean number of alleles per locus $\left(N_{\mathrm{A}}\right)$, mean number of allelic richness $\left(A_{R}\right)$, the probability results of Wilcoxon tests under three different models (IAM, SMM, and TPM) for Bottleneck and frequency of family relationship (ML-Relate; Freq. fam.).

\begin{tabular}{|c|c|c|c|c|c|c|c|}
\hline \multirow[t]{2}{*}{ Site } & \multirow[t]{2}{*}{$\mathrm{N}$} & \multirow[t]{2}{*}{$N_{\mathrm{A}}$} & \multirow[t]{2}{*}{$A_{\mathrm{R}}$} & \multicolumn{3}{|c|}{ Bottleneck } & \multirow[t]{2}{*}{ Freq. fam. } \\
\hline & & & & IAM & SMM & TPM & \\
\hline Yangsan & 31 & 15.27 & 11.57 & 0.339 & 0.979 & 0.999 & 0.028 \\
\hline Jincheon & 29 & 14.00 & 10.48 & 0.980 & 0.999 & 1.000 & 0.015 \\
\hline
\end{tabular}

IAM = infinite allele model; SMM = stepwise mutation model; TPM = two-phased model.

The two sites analyzed in the present study showed significant genetic differentiation between each other (pairwise $-F_{\mathrm{ST}}=0.110, \mathrm{P}<0.001$; pairwise- $R_{\mathrm{ST}}=0.124, \mathrm{P}<0.001$ ). Such detectable genetic differentiation between two sites could relate to a long history of geographic isolation. In addition to geographic distance, those two sites might have been isolated from each other by complex mountain ranges and by the signature of geological uplifts (Kyung, 2010), which probably limited the level of gene flow between them. A more comprehensive resolution of population 
structure and dispersal could be obtained by extensive sampling throughout most of its distribution range (i.e., the Korean Peninsula and east China) and genotyping the loci characterized here.

Upon maximum likelihood calculation of relatedness within sites by ML-Relate, an extremely low level of family relatedness was found at both sites (Table 2), indicating that the microsatellites used here are highly informative for parentage analysis. With a high statistical power in parentage and sibship exclusion, these microsatellite loci will be suitable for the identification of individuals in studies of reproductive success and mating systems and in captive breeding practice as well as in the evaluation of cryptic diversity, population genetic structure, and metapopulation dynamics. Further study will include tests of cross-amplification across different species (or lineages) in the Rugosa complex as well as in Ranidae.

\title{
Conflicts of interest
}

The authors declare no conflict of interest.

\section{ACKNOWLEDGMENTS}

\author{
Research supported by the National Research Foundation of Korea (\#NRF- \\ 2012R1A1A2040065).
}

\section{REFERENCES}

Crawford AJ, Lips KR and Bermingham E (2010). Epidemic disease decimates amphibian abundance, species diversity, and evolutionary history in the highlands of central Panama. Proc. Natl. Acad. Sci. U. S. A. 107: 13777-13782. http://dx.doi.org/10.1073/pnas.0914115107

Excoffier L and Lischer HEL (2010). Arlequin suite ver 3.5: a new series of programs to perform population genetics analyses under Linux and Windows. Mol. Ecol. Resour. 10: 564-567.http://dx.doi.org/10.1111/j.1755-0998.2010.02847.x

Frost DR, Grant T, Faivovich J, Bain RH, et al. (2006). The amphibian tree of life. Bull. Am. Mus. Nat. Hist. 297: 1-370. http://dx.doi.org/10.1206/0003-0090(2006)297[0001:TATOL]2.0.CO;2

Garza JC and Williamson EG (2001). Detection of reduction in population size using data from microsatellite loci. Mol. Ecol. 10: 305-318.http://dx.doi.org/10.1046/j.1365-294x.2001.01190.x

Gower DJ, Bahir MM, Mapatuna Y, Pethiyagoda R, et al. (2005). Molecular phylogenetics of Sri Lankan Ichthyophis (Amphibia: Gymnophiona: Ichthyophiidae), with discovery of a cryptic species. Raffles Bull. Zool. 12: 153-161.

Goudet J (2001). FSTAT, a program to estimate and test gene diversities and fixation indices Version 2.9.3. Available at [http:// www.unil.ch/izea/softwares/fstat.html]. Accessed May 12, 2015.

Guo SW and Thompson EA (1992). Performing the exact test of Hardy-Weinberg proportion for multiple alleles. Biometrics 48 : 361-372.http://dx.doi.org/10.2307/2532296

Hanken J (1999). Why are there so many new amphibian species when amphibians are declining? Trends Ecol. Evol. (Amst.) 14: 7-8.http://dx.doi.org/10.1016/S0169-5347(98)01534-1

Hayes TB, Falso P, Gallipeau S and Stice M (2010). The cause of global amphibian declines: a developmental endocrinologist's perspective. J. Exp. Biol. 213: 921-933.http://dx.doi.org/10.1242/jeb.040865

Kalinowski ST, Wagner AP and Taper ML (2006). ML-Relate: a computer program for maximum likelihood estimation of relatedness and relationship. Mol. Ecol. Notes 6: 576-579. http://dx.doi.org/10.1111/j.1471-8286.2006.01256.x

Kyung JB (2010). Paleoseismological study and evaluation of Maximum Earthquake Magnitude along the Yangsan and Ulsan fault zone in the southern part of Korea. Geophysics Geophys. Explor. 13: 187-197.

Lemmon EM, Lemmon AR and Cannatella DC (2007). Geological and climatic forces driving speciation in the continentally distributed trilling chorus frogs (Pseudacris). Evolution 61: 2086-2103.http://dx.doi.org/10.1111/j.1558-5646.2007.00181.x

Máeda N and Matsui M (1999). Frogs and toads of Japan. Revised edition. Bun-Ichi Sogo Shuppan: Tokyo.

Miura I (2007). An evolutionary witness: the frog rana rugosa underwent change of heterogametic sex from XY male to $\mathrm{ZW}$ female. Sex Dev. 1: 323-331.http://dx.doi.org/10.1159/000111764 
Nair A, Gopalan SV, George S, Kumar KS, et al. (2012). High cryptic diversity of endemic Indirana frogs in the western Ghats biodiversity hotspot. Anim. Conserv. 15: 489-498. http://dx.doi.org/10.1111/j.1469-1795.2012.00539.x

Park HC, Suk HY, Jeong EJ, Park DS, et al. (2014). Population genetic structure of endangered Mongolian racerunner (Eremias argus) from the Korean Peninsula. Mol. Biol. Rep. 41: 7339-7347.http://dx.doi.org/10.1007/s11033-014-3623-6

Piry S, Luikart G and Cornuet JM (1999). BOTTLENECK: a computer program for detecting recent reductions in the effective population size using allele frequency data. J. Hered. 90: 502-503. http://dx.doi.org/10.1093/jhered/90.4.502

Raymond M and Rousset F (1995). GENEPOP, version 1.2: population genetics software for exact tests and ecumenicism. $J$. Hered. 86: 248-249.

Rice W (1989). Analyzing tables of statistical tests. Evolution 43: 223-225. http://dx.doi.org/10.2307/2409177

Sekiya K, Miura I and Ogata M (2012). A new frog species of the genus Rugosa from Sado Island, Japan (Anura, Ranidae). Zootaxa 3575: 49-62.

Stuart SN, Chanson JS, Cox NA, Young BE, et al. (2004). Status and trends of amphibian declines and extinctions worldwide. Science 306: 1783-1786.http://dx.doi.org/10.1126/science.1103538

Suk HY, Neff BD, Fitzpatrick JL and Balshine S (2009). Isolation and characterization of polymorphic microsatellite loci in plainfin midshipman fish. Hereditas 146: 204-207.http://dx.doi.org/10.1111/j.1601-5223.2009.02140.x

Vieites DR, Wollenberg KC, Andreone F, Köhler J, et al. (2009). Vast underestimation of Madagascar's biodiversity evidenced by an integrative amphibian inventory. Proc. Natl. Acad. Sci. USA 106: 8267-8272.http://dx.doi.org/10.1073/pnas.0810821106

Wynn A and Heyer WR (2001). Do geographically widespread species of tropical amphibians exist? an gstimate of Genetic relatedness within the neotropical frog Leptodactylus fuscus (Schneider 1799) (Anura Leptodactylidae). Trop. Zool. 14: 255-285. http://dx.doi.org/10.1080/03946975.2001.10531157

Yang SY, Min MS, Kim JB, Suh JH, et al. (2000). Genetic diversity and speciation of Rana rugosa (Amphibi; Ranidae). Korean J. Biol. Sci. 4: 23-30. http://dx.doi.org/10.1080/12265071.2000.9647519 